\title{
Predictors of European League Against Rheumatism (EULAR) good response, DAS-28 remission and sustained responses to TNF- inhibitors in rheumatoid arthritis: a prospective study in refractory disease
}

\author{
Reem Hamdy A Mohammed ${ }^{1,2^{*}}$, Faisal Farahat ${ }^{3,4}$, Hanady H Kewan ${ }^{5,6}$ and Mohammed A Bukhari ${ }^{2}$
}

\begin{abstract}
The aim of this study was to survey factors related to EULAR good response, the DAS-28 definition of remission, ACR 50 response, sustained response to tumor necrosis factor inhibitors (TNF-I) therapy in biologic naïve patients with refractory rheumatoid arthritis. This was a single center observational clinical prospective 2 years' study, EULAR response criteria, DAS 28, HAQ and radiographic changes were recorded. Eighty patients included (64 females and 16 males, mean age was $48.4+-17.9$ years, mean disease duration $7.3+-5.9$ years). At 6 months $70 \%$ achieved EULAR good response, 51.8\% achieved DAS-28 remission. Good response/sustained responses inversely correlated with baseline DAS-28 and radiographic erosions $P<0.05$. EULAR good response/remission by 6 months, sustained response at 2 years positively correlated with the decline in $R F$ titers $(r=0.33, P<0.05 \& r=0.30, P<0.03$ respectively), negatively correlated with the baseline HAQ. Regression analysis identified higher serum hemoglobin concentration, lower baseline HAQ scores, and the absence of radiographic erosions as significant predictors of good as well as sustained responses after adjustment for potential covariates. Methotrexate was associated with favorable responses and remission at 6 months (ORs $=1.13,1.30$ respectively). The study concluded that a lower baseline DAS-28 and HAQ scores, the lack of radiographic erosions favored EULAR good response and were significant predictors of sustained response to TNF-I.
\end{abstract}

Keywords: EULAR good response; DAS-28 remission; Sustained responses; Refractory rheumatoid arthritis; Tumor necrosis factor inhibitors

\section{Introduction}

Rheumatoid Arthritis is a systemic autoimmune inflammatory disease of indefinite etiology. The disease specifically affects the synovial joints contributing to significant synovial inflammation, progressive joint destruction and deformity of the affected joints. RA affects approximately $1 \%$ of adults all over the world with the diagnosis usually established between the third and fifth decade of life.

\footnotetext{
* Correspondence: rmhamdy@yahoo.com

'Rheumatology and Clinical Immunology, Department of Rheumatology and Rehabilitation, School of Medicine, Cairo University Hospitals, Cairo, Egypt ${ }^{2}$ Internal Medicine Department, Alhada Armed Forces Hospital, Taif, Kingdom of Saudi Arabia

Full list of author information is available at the end of the article
}

Women are 2 to 3 times more likely to be diagnosed than men. The disease might additionally contribute to extraarticular multi-organ inflammation with variable outcome. Improperly treated the disease might lead to significant morbidity and incapacitation. For decades the conventional synthetic DMARDs (csDMARDs) have been the corner stone for the management of RA with methotrexate being the anchor drug in most of the designed regimens. Multiple studies and real life reports have documented that even with the highest standards of care with the use of csDMARDs either alone or in combinations up to $60 \%$ of the affected cases with RA fail to achieve successful remission. Within the last decade the field of therapeutics have witnessed an evolution in the 
treatment armamentarium of rheumatoid arthritis with the lead of the Tumor necrosis factor inhibitors (TNF-I) as the first line biologic drugs (Burmester GR et al. 2012; Wolfe and Michaud 2010; Nozaki et al. 2013; Mohammed et al. 2014; Nam et al. 2010; Hetland et al. 2010; Gartlehner et al. 2006; Wolfe and Michaud 2010; Gaujoux-Viala et al. 2010).

The aim of the current study was to prospectively survey the factors related to achieving an EULAR good/remission using the DAS-28 disease activity score and investigate predictors of a sustained response in a population of biologic naïve patients with refractory rheumatoid arthritis who receive tumor necrosis factor inhibitors TNF-I.

\section{Methods}

This is a single center observational clinical study in a cohort of biologic naïve Refractory RA patients initiating their first line biologic treatment of TNF-inhibitors (infliximab, adalimumab or etanercept each administered based on an agreement between the patient and the treating physician with special considerations). The study was conducted at the Rheumatology section/Internal Medicine Department, Alhada Armed Forces Hospital, Kingdom of Saudi Arabia throughout a period of two years October 2010- October 2012. TNF-Is were given as recommended by the manufacturers (Infliximab 3-5 $\mathrm{mg} / \mathrm{kg}$ intravenous infusion, Adalimumab $40 \mathrm{mg}$ subcutaneous every 2 weeks, etanercept $50 \mathrm{mg}$ subcutaneous weekly). Authors used the STROBE guidelines for observational studies for construction of their research checklist. The study was approved by the organizational ethics committee and was conducted in accordance with World Medical Association Helsinki Declaration of ethics (Adopted by the 18th WMA General Assembly, Helsinki, Finland, June 1964). All the patients included gave informed consents prior to the initiation of TNF-I biologic therapy.

\section{Inclusion criteria:}

- All patients who satisfied the ACR/EULAR 2010 for early rheumatoid arthritis or ACR-1997 criteria for established RA.(Arnett et al. 1988; Aletaha et al. 2010)

- Biologic naïve RA patients who failed to achieve remission or low disease activity despite cs DMARDs monotherapy or combinations for at least 6 months.

\section{Exclusion criteria:}

- RA patients who were previously or are currently receiving biologic drugs.

- Patients with autoimmune diseases other than RA.
- Infections: tuberculosis, hepatitis B, C, other active or incompletely treated bacterial, viral or fungal infections.

- Patients with heart failure grade III-IV NYHA, interstitial pulmonary disease, untreated malignancies.

Data were prospectively gathered over a follow up period of 2 years. The following clinical data were recorded; patients' demographics, simplified 28 swollen tender joint score Disease Activity Score (DAS 28), ACR 50 response, disability score using health assessment questionnaire (HAQ score of $0-3$ based on severity of functional impairment), visual analogue scale pain score (VAS-pain with $0=$ no pain and $10=$ very severe pain), assessment for the presence of radiographic erosions and serology profile (rheumatoid factor, anti-citrullinated C peptide) were recorded. The primary outcome measure of the study was to identify responders who achieved the European League Against Rheumatism (EULAR) good responses as assessed by DAS score at 6 months (VAN GESTEL AM et al. 1996) and survey the major differences between responders versus non responders that favored an early good response or remission, ACR-50 responses at 6 months were additionally taken. The secondary outcome measure was to identify the percentage of patients sustaining their response over 2 years. Patients who fail to respond to the introduced 1st TNF-I or lose response to one anti TNF will be classified as non- responders.

\section{Statistical analysis}

Statistical analysis was performed using SPSS (Statistical Package for the Social Science; SPSS Inc., Chicago, IL, USA) version 19 for Microsoft Windows. Quantitative data were statistically described in terms of mean and standard deviations $( \pm S D)$, qualitative data were presented as median and interquartile ranges. Within group comparison of quantitative variables was done using Anova F-test with posthoc multiple group comparisons. For comparing categorical variables, Chi square $\left(\chi^{2}\right)$ test was performed. Exact test was used instead when the expected frequency is less than 5 . P values less than 0.05 was considered statistically significant. Pearson correlation was used for quantitative variables, spearman rank correlation was used for qualitative variables. Multivariate logistic regression analysis was used for identification of factors associated with good EULAR response/ remission response at 6 months and predictors of sustained response at 2 years in the study group.

\section{Results}

A total of 80 patients were included in the study 64 females (80\%) and 16 males (20\%), having a mean age of $48.4+-17.91$ years a mean disease duration of $7.29+-3.93$ years and a mean baseline DAS- 28 of $6 \pm 1$, 
HAQ of $1.25+-0.35$, mean ESR of $51.00 \pm 25.30 \mathrm{~mm} / \mathrm{hr}$, mean CRP of $35.18+-31.65 \mathrm{mg} / \mathrm{l}$. Radiographic erosions were detected in $50 \%(n=40)$ of the study population at baseline. The baseline demographic and clinical characteristics are displayed in Table 1.

At 6 months from initiation of therapy results showed that Thirty patients were receiving adalimumab, 30 patients receiving infliximab and 20 patients receiving etanercept. Results of the study revealed that by completion of 6 months from initiation of therapy $70 \%$ of the patients (56) achieved the EULAR good response, with $51.8 \%$ patients $(n=29)$ of the 56 responders having achieved DAS-28 definition of remission $(<2.6)$. The baseline differences between the EULAR good responders and the inadequate responders are displayed in Tables 2 and 3.

\section{Analysis of correlations between the different disease related parameters and the type of response perceived with TNF-I therapy results of this study showed that} At 6 months achieving the EULAR good response using the DAS-28/ or achieving DAS-28 definition for remission directly correlated with a high positive titers of IgM rheumatoid factor and higher $\mathrm{Hb} \%$ at baseline $(r=0.30 \& 0.30$, $\mathrm{P}<0.05$, respectively) and inversely correlated with baseline DAS-28 and radiographic scoring $(r=-0.81 \&-0.75$, $\mathrm{P}<0.01$ respectively).

Table 1 The baseline demographic and clinical characteristics of the study group

\begin{tabular}{lll}
\hline Descriptive parameter & Range & Mean \pm S.D \\
\hline Age & $16-85$ years & $48.26 \pm 17.91$ \\
Disease duration & $1-20$ years & $7.29 \pm 3.93$ \\
ESR & $8-119 \mathrm{~mm} / \mathrm{hr}$ & $51.00 \pm 25.30$ \\
CRP & $6-136.50 \mathrm{mg} / \mathrm{l}$ & $35.18 \pm 31.65$ \\
Hemoglobin & $10-16 \mathrm{gm} / \mathrm{dl}$ & $11.56 \pm 1.30$ \\
Rheumatoid factor & $0-849$ & $141.09 \pm 157.88$ \\
Anti-CCP & $0-450$ & $230.05 \pm 156.35$ \\
DAS & $3-7.5$ & $6.0 \pm 1.0$ \\
HAQ & $0.5-8$ & $1.30 \pm 0.71$ \\
VAS & $5-10$ & $6.70 \pm 0.95$ \\
Medications: & Number of patients & Percentage\% \\
Conventional DMARDs & 58 & 72.5 \\
Methotrexate & 64 & 80 \\
Oral corticosteroids & 53 & 66.2 \\
Non-steroidal drugs & 80 & 100 \\
\hline Abbrevation: ESR: & $5 y+5$ &
\end{tabular}

Abbreviations: ESR: erythrocyte sedimentation rate, CRP: C- reactive protein, Anti-CCP: anti-citrullinated $C$ peptide, DAS-28: disease activity score, $H A Q$ : health assessment questionnaire, VAS: visual analogue scale for pain.

\section{At 2 years}

Results showed that 38 patients out of the initially responding 56 patients (corresponding to $47.5 \%$ of the population studied, $67.8 \%$ of the responders) were still sustaining their initial good response by the completion of 2 years of follow up. Eighteen patients were considered as non-responders including 10 patients who developed secondary loss of response and were shifted to a second line biologic, while 8 patients dropped out of the study. Results showed that a sustained response at 2 years positively correlated with sero-positivity to RF and baseline $\mathrm{Hb} \%(\mathrm{r}=0.30 \& 0.33, \mathrm{P}<0.05$ respectively $)$ and inversely correlated with baseline DAS-28, HAQ and radiographic erosions $(\mathrm{r}=-0.85,-0.74,-0.77$ respectively, $\mathrm{P}<0.01$ ). The details of the correlations between the different assessment parameters and the treatment outcome in the studied patients are displayed in Table 4.

\section{Multivariate regression analysis}

After adjustment for confounders showed that the concomitant use of methotrexate was identified as a positive predictor of good EULAR response and DAS-28 remission at 6 months $(\mathrm{ORs}=1.13,1.30, \mathrm{CI}=0.15-2.2,0.37$ 10.8 , respectively), also the use of csDMARDs combinations was associated by EULAR good response (ORs = $1.35, \mathrm{CI}=0.07-7.36$ ). On the other hand, a higher baseline DAS was identified as a negative predictor for a good EULAR $(\mathrm{ORs}=1.20, \mathrm{CI}=3.23-31.78)$. However, the use of oral corticosteroids didn't prove to affect the type of response in the studied patients $(P>0.05)$. The study couldn't find any significant predictive value for variations in age, gender, or disease duration.

At the end of the study period (completion of 2 years follow up) results of regression analysis showed that the presence of higher baseline serum hemoglobin concentrations, sero-positivity to IgM rheumatoid factor were in favor of a better response yet significance value was weak whereas, a lower baseline HAQ score (corresponding to lesser functional disability) and the absence of radiographic erosions at inclusion as significant predictors of sustained response to TNF-I in the studied group Table 5 .

\section{Discussion}

The introduction and progressive developments of biologic disease modifying anti- rheumatic drugs have greatly influenced the treatment paradigm as well as treatment outcome in patients with inflammatory arthritis. Till present even with the amazing advent in this domain together with the expanding list of biologic DMARDs, anti-tumor necrosis factor therapy or tumor necrosis factor inhibitors remain on top of the list. The comparative effectiveness of the three commonly used anti-TNF infliximab, etanercept and adalimumab didn't 
Table 2 The differences between responders and non responders at inclusion in the study (0 months of follow up)

\begin{tabular}{llll}
\hline Parameter & $\begin{array}{l}\text { Responders }(\mathbf{n = 5 6 )} \\
\text { Mean } \pm \text { S.D }\end{array}$ & $\begin{array}{l}\text { Non-responders }(\mathbf{n}=\mathbf{2 4}) \\
\text { Mean } \pm \text { S.D }\end{array}$ & $\begin{array}{l}\text { Significance } \\
\mathbf{P} \text {-value }\end{array}$ \\
\hline Age & $47.84 \pm 18.89$ & $49.64 \pm 15.70$ & $\mathrm{P}>0.05$ \\
Disease duration & $7.66 \pm 4.11$ & $6.59 \pm 3.41$ & $\mathrm{P}>0.05$ \\
Rheumatoid factor titers & $169.95 \pm 176.19$ & $73.80 \pm 74.58$ & $\mathrm{P}<0.01^{* *}$ \\
ESR & $51.40 \pm 24.70$ & $49.97 \pm 26.93$ & $\mathrm{P}>0.05$ \\
C-reactive protein & $36.12 \pm 34.27$ & $33.10 \pm 25.19$ & $P>0.05$ \\
Baseline-HAQ & $1.25 \pm 0.33$ & $1.24 \pm 0.34$ & $P>0.05$ \\
Baseline DAS-28 & $6.32 \pm 0.62$ & $5.34 \pm 1.38$ & $P<0.01^{* *}$ \\
Baseline VAS & $6.77 \pm 0.97$ & $6.51 \pm 0.90$ & $P>0.05$ \\
Hemoglobin & $11.59 \pm 1.30$ & $11.36 \pm 1.06$ & $P>0.05$ \\
\hline
\end{tabular}

*P-value: significant < 0.05. **P-value: highly significant < 0.01. Abbreviations: ESR: erythrocyte sedimentation rate, $H A Q$ : health assessment questionnaire, $D A S$ : disease activity score, VAS: visual analogue scale.

vary significantly as has been shown in various studies including one meta-analysis of 26 published placebocontrolled RCTs of patients with RA in MTX-resistant populations where the investigators weren't able to show significant variations in efficacy among the 3 TNF inhibitors. (Hetland et al. 2010; Gartlehner et al. 2006) Despite the multiplicity of such published trials discussing the efficacy of biologic Tumor necrosis Factor inhibitors in refractory rheumatoid arthritis (RA), studies displaying predictors of good response to such therapy in the daily life clinical practice remain insufficient and heterogeneous demanding continued testing of such predictors within different ethnic populations and at different levels of rheumatology practice (Scott and Kingsley 2006; Taylor and Feldmann 2009; Grewal 2009; Canhão et al. 2012).

To our knowledge this study is the first to scrutinize predictors of response to TNF-I in patients with refractory RA who started their first line TNF-I and were prospectively followed up for response over 2 years in this region of KSA. This was a single center prospective observational study that included eighty RA patients who were eligible for inclusion and consented to receive TNF-I biologic therapy. The goal of this study wasn't to measure comparative effectiveness of the three used TNF-I to each other but to investigate factors related to

Table 3 The main differences in the defined assessment measures with TNF-I at 6 months

\begin{tabular}{llll}
\hline Measures & Responders & Non responders & $\begin{array}{l}\text { Significance } \\
\text { P-value }\end{array}$ \\
\hline ESR & $23.56 \pm 13.58$ & $28 \pm 16.87$ & $<0.05^{*}$ \\
CRP & $6.66 \pm 4.81$ & $14.82 \pm 17.90$ & $<0.05^{*}$ \\
Hb\% & $12.61 \pm 1.09$ & $12.01 \pm 0.87$ & $>0.05$ \\
DAS-28 & $2.80 \pm 1.15$ & $4.35 \pm 1.24$ & $<0.05^{*}$ \\
RF at 6 months & $118.84 \pm 127.55$ & $66.60 \pm 74.16$ & $<0.05^{*}$ \\
\hline
\end{tabular}

${ }^{*} \mathrm{P}$ value $<0.05$ is considered statistically significant. achieving an early EULAR good response/remission (remission is defined as DAS score $<2.6$ ) as assessed by changes in DAS-28 score at 6 months and to pick up possible predictors of sustained response to therapy by completion of the study period (2 years). Patients who achieved a good response or went into remission at 6 months were classified as responders, whereas patients who failed to achieve a satisfying response, developed drug related serious adverse events or were shifted to another biologic were considered as non-responders. The study successfully completed the observation and recording of the desired outcome measures with results at 6 months showing that the majority of the RA population included $(70 \%, \mathrm{n}=56)$ achieved a good EULAR response on TNF-I, with more than half of the responders $51.8 \%(n=29)$ satisfying the DAS-28 definition of remission at 6 months. The study showed that RA patients who achieved an early response at 6 months were found to have significantly higher IgM rheumatoid factor titers at baseline compared to non-responders (mean $169.95 \pm 176.19 \mathrm{mg} / \mathrm{l}, \mathrm{P}<0.01)$. Such statistical conclusions were further supported by results of the correlations between the patterns of responses perceived during the assessment period and the baseline (at inclusion) disease related/patient related features. The study found that an early good response and/or remission at 6 month significantly correlated with higher Ig $\mathrm{M}$ rheumatoid factor titers and higher hemoglobin concentrations at inclusion, yet inversely correlated with the baseline DAS-28, the HAQ score and the presence of radiographic erosions. At 2 years the study showed that $67.8 \%$ of the responders were still sustaining their response to TNF-I. The pertinence of sustained response at 2 years positively correlated with sero-positivity to $\mathrm{RF}$ and $\mathrm{Hb} \%$ at inclusion and inversely correlated with baseline DAS-28, HAQ and radiographic scoring. The continued use of methotrexate as an anchor drug was associated with a good EULAR response and DAS-28 remission at 6 months, also 
Table 4 The correlations between the different assessment parameters and the treatment outcome in the studied patients

\begin{tabular}{llll}
\hline Parameter & $\begin{array}{l}\text { EULAR good } \\
\text { response } \\
\text { At 6 months }\end{array}$ & At 6 months & $\begin{array}{l}\text { At 2 years } \\
\text { response }\end{array}$ \\
\hline Disease duration & $r=-0.16$ & $r=-0.05$ & $r=-0.10$ \\
& $P>0.05$ & $P>0.05$ & $P>0.05$ \\
Positive IgM RF & $r=0.30$ & $r=0.31$ & $r=0.30$ \\
at baseline & $P=<0.05^{*}$ & $P<0.05^{*}$ & $P<0.05^{*}$ \\
Positive Anti-CCP & $r=0.18$ & $r=0.08$ & $r=0.14$ \\
at baseline & $P>0.05$ & $P=0.35$ & $P>0.05$ \\
Baseline & $r=0.39$ & $r=0.30$ & $r=0.33$ \\
Hemoglobin & $P<0.05^{*}$ & $P<0.05^{*}$ & $P<0.05^{*}$ \\
Baseline DAS 28 & $r=-0.81$ & $r=-0.74$ & $r=-0.85$ \\
Baseline HAQ & $P=0.01^{* *}$ & $P<0.01^{* *}$ & $P<0.01^{*}$ \\
Baseline VAS & $r=0.08$ & $r=-0.18$ & $r=-0.74$ \\
& $P>0.05$ & $P<0.05^{*}$ & $P<0.01^{* *}$ \\
Baseline & $r=0.05$ & $r=-0.06$ & $r=-0.17$ \\
Radiographic & $P<0.01^{* *}$ & $P>0.05$ & $P>0.05$ \\
erosions & $r=0.33$ & $r=-0.80$ & $r=-0.77$ \\
Declining RF & $P=0.01^{* *}$ & $P<0.01^{* *}$ \\
titers & $P<0.05^{*}$ & $r=0.30$ & $r=0.30$ \\
\hline
\end{tabular}

*P-value: significant $<0.05$. ${ }^{*}$ P-value: highly significant $<0.01$. Abbreviations: ESR: erythrocyte sedimentation rate, HAQ: health assessment questionnaire, $D A S$ : disease activity score, VAS: visual analogue scale.

the use of conventional synthetic DMARDs (cs DMARDs) in combination with the used TNF-I was associated by EULAR good response and ACR 50 responses. However, the use of oral corticosteroids (prednisolone) wasn't shown to affect the type of response in the studied patients. Higher baseline DAS was identified as a negative predictor for a good EULAR and DAS remission, sustained response and/ or ACR 50 responses. Disease duration didn't appear to affect the response to biologic therapy in the studied population. The study couldn't find any significant predictive value for variations in age, gender, or disease duration among the studied RA patients.

Results of the current study didn't seem far from that reported in late studies including some trials by the British study (BSRBR) by Hyrich et al. 2006, GISEA study by Mancarella et al. 2007, the ReAct study by Bombardieri et al. 2007, Kristensen et al. 2008 and the German study by Kleinert et al. 2012, amongst others in several points particularly regarding continued use of baseline methotrexate or conventional DMARDS in combination with biologics. (Kristensen et al. 2008; Hyrich et al. 2006; Kleinert et al. 2012; Mancarella et al. 2007; Bombardieri et al. 2007; Breedveld et al. 2006; Maini et al. 1999; Van der Heijde et al. 2007; St
Table 5 Factors related to sustained responsiveness in the study population

\begin{tabular}{ll}
\hline Parameter & Significance \\
\hline Disease duration & $\mathrm{t}=-1.92$ \\
ESR & $\mathrm{P}=0.05$ \\
& $\mathrm{t}=-0.98$ \\
CRP & $\mathrm{P}=0.32$ \\
& $\mathrm{t}=0.09$ \\
Hemoglobin & $\mathrm{P}=0.92$ \\
Rheumatoid factor & $\mathrm{t}=3.71$ \\
Anti-CCP & $\mathrm{P}=0.0001^{* *}$ \\
& $\mathrm{t}=2.17$ \\
DAS-28 & $\mathrm{P}=0.03$ \\
HAQ & $\mathrm{t}=0.10$ \\
& $\mathrm{P}=0.91$ \\
& $\mathrm{t}=-0.27$ \\
& $\mathrm{P}=0.78$ \\
& $\mathrm{t}=-2.71$ \\
& $\mathrm{P}=0.008^{* *}$ \\
& $\mathrm{t}=-2.01$ \\
& $\mathrm{P}=0.04^{*}$ \\
& $\mathrm{t}=-1.01$ \\
& $\mathrm{P}=0.92$ \\
& $\mathrm{t}=-2.20$ \\
& $\mathrm{P}=0.03^{*}$ \\
&
\end{tabular}

*P-value: significant $<0.05$. **P-value: highly significant $<0.01$. Abbreviations: ESR: erythrocyte sedimentation rate, $H A Q$ : health assessment questionnaire, DAS: disease activity score, VAS: visual analogue scale.

Clair et al. 2004; Nozaki et al. 2010; Potter et al. 2009) The authors could identify the use of methotrexate and conventional DMARDs as significant contributors to good clinical outcomes a conclusion shared by the current study. Additionally important results of the current study illustrated that a low HAQ corresponding to a better functional status and low DAS score at inclusion favored a good early response to biologic TNF-I. Unlike that reported by Hetland et al. 2010, were the authors found that older age and concomitant use of corticosteroids were negative predictors of good response, (Hetland et al. 2010) the study wasn't able to detect any significant influence of age, gender or oral corticosteroid use on the pattern or timing of responses recorded.

The existence of RF especially IgM-RF (Abs to conserved region of IgG class Igs) with the combined detection of additional isotypes IgA-RF remain one of the diagnostic criteria in RA and in multiple reports its' existence in high titers corresponded to severe erosive disease mandating aggressive therapy. There has been a lot of conflicting results regarding the influence of TNF-I and conventional DMARDs on serum RF levels in RA as well as the possible 
influence of higher titers of RF on the pattern of responses to TNF-I. The exact mechanisms by which TNF-I affect rheumatoid factor remains unclear as it is not known whether TNF-I are capable of direct blockage of RF production or not. However, infliximab therapy has been proven to reduce the number of synovial infiltration cells, including plasma cells. RF-producing cells are present in the inflamed rheumatoid synovium and because the local environment may favour synovial RF production, rheumatologists might expect that the reduction in inflammatory lymphoplasmacytic infiltration into the rheumatoid synovium would contribute to a reduced production of RF. A number of published studies coincided in the finding that a positive IgM RF was related to a poor response to TNF-I, other studies found a correlation between the declining levels of autoantibodies with TNF-I and the response, whilst in a late study by Klaasen et al. 2009 and another meta-analysis by Salgado et al. 2014 the investigators reported that a positive RF status doesn't correlate with the EULAR good response or remission. In the current study the investigators identified that patients with higher baseline IgM rheumatoid factor and higher baseline hemoglobin achieved a better response on anti-TNF therapy, however the correlations were of moderate to weak significance furthermore, the achievement of good response and remission correlated with the decline in rheumatoid factor titers which was also a weak correlation. Such finding has been reported in some other studies (Nozaki et al. 2010; Potter et al. 2009; Klaasen et al. 2009; Salgado et al. 2014; Atzeni et al. 2006; Yazdani-Biuki et al. 2005; Smeets et al. 2003; Klaasen et al. 2011; Bruns et al. 2009; Bobbio-Pallavicini et al. 2007).

Because results of clinical trials do not always mirror an exact of what rheumatologists face in real life daily practice, observational studies and short reports still represent an important contributor to the knowledge bank in the field of research concerning the use of biologic DMARDs in refractory RA. Despite that researchers might face the challenge that such studies are usually open labelled non-randomized which might generate methodological limitation such drawback can be minimized by avoidance of separate analysis.

\section{Conclusions}

In this study, a lower baseline DAS-28 and HAQ scores as well as the absence of radiographic erosions showed a highly significant correlation with good EULAR response, remission and sustained responses. While a higher baseline hemoglobin concentrations, a lower baseline HAQ score and the absence of radiographic erosions were identified as significant predictors of sustained responses to TNF-I in the studied patients with refractory RA. The use of combination therapy particularly with methotrexate favored an earlier good response and remission by 6 months. Good response to TNF-I and sustained responses showed some correlation with the decline in RF titers during observation a finding that demands further investigations in upcoming researches.

The limited sample size represents one limitation of the study and authors recommend encouraging similar studies in the field to provide a sufficient bank of evidences regarding predictors of response to first and second line biologics in refractory disease.

\section{Competing interests}

The authors declare that they have no competing interests.

\section{Authors' contributions}

RHAM was actively involved in designing the research plan, clinical assessment and follow up of the study population, conduction and interpretation of statistical analysis, manuscript writing, revision and publishing requirements. FF was involved in designing research plan and statistical analysis. HK was involved in radiographic assessment of the studied patients. MB actively participated in gathering of clinical data along the study period. All authors read and approved the final manuscript.

\section{Acknowledgments}

The authors would like to thank the research department and the internal medicine department at Alhada Armed forces Hospital, Taif, KSA for facilitating the conduction of this study, their unlimited support and encouragement.

\section{Author details}

${ }^{1}$ Rheumatology and Clinical Immunology, Department of Rheumatology and Rehabilitation, School of Medicine, Cairo University Hospitals, Cairo, Egypt. IInternal Medicine Department, Alhada Armed Forces Hospital, Taif, Kingdom of Saudi Arabia. ${ }^{3}$ Community Medicine, Munofia University, Munofia, Egypt. ${ }^{4}$ Research Department Al Hada Armed Forces Hospital, Taif, Kingdom of Saudi Arabia. ${ }^{5}$ Department of Radio-diagnosis, Faculty of Medicine, Mansoura University, Mansoura, Egypt. ${ }^{6}$ Alhada Armed Forces Hospital, Taif, Kingdom of Saudi Arabia.

Received: 10 April 2015 Accepted: 13 April 2015

Published online: 01 May 2015

\section{References}

Aletaha D, Neogi T, Silman A, Funovits J, Felson DT, Bingham CO, Birnbaum NS, Burmester GR, Bykerk VP, Cohen MD, Combe B, Costenbader KH, Dougados M, Emry P, Ferracioli G, Hazes JMW, Hobbs K, Huizinga TWJ, Kavanaugh A, Kay J, Kvien TK, Laing T, Mease P, Menard HA, Moreland LW, Naden RL, Pincus T, Smolen JS, Stanislawska-Biernat E, Symmons D, Tak PP, et al: (2010) 2010 Rheumatoid Arthritis

Classification Criteria An American College of Rheumatology/European League Against Rheumatism Collaborative Initiative. Arthritis Rheum 62(9):2569-2581

Arnett FC, Edworthy SM, Bloch DA, McShane DJ, Fries JF, Cooper NS, Healey LA Kaplan SR, Liang MH, Luthra HS, Medsger TA, Mitchell DM, Neustadt DH, Pinals RS, Schaller JG, Sharp JT, Wilder RL, Hunder GG (1988) The American Rheumatism Association 1987 revised criteria for the classification of rheumatoid arthritis. Arthritis Rhe um 31:315-324

Atzeni F, Sarzi-Puttini P, Dell' Acqua D, De Portu S, Cecchini G, Cruini C (2006) Adalimumab clinical efficacy is associated with rheumatoid factor and anti-cyclic citrullinated peptide antibody titer reduction: a one-year prospective study. Arthritis Res Ther 8:3

Bobbio-Pallavicini F, Caporali R, Alpini C, Avalle S, Epis OM, Klersy C (2007) High $\lg$ A rheumatoid factor levels are associated with poor clinical response to tumour necrosis factor a inhibitors in rheumatoid arthritis. Ann Rheum Dis 66:302-307

Bombardieri S, Ruiz AA, Fardellone P, Geusens P, McKenna F, Unnebrink K, Oezer U (2007) Effectiveness of adalimumab for rheumatoid arthritis in patients with a history of TNF-antagonist therapy in clinical practice. Rheumatology 46:1191-1199

Breedveld FC, Weisman MH, Kavanaugh AF, Cohen SB, Pavelka K, Van Vollenhoven R, Sharp J, Perez JL, Spencer-Green GT (2006) The PREMIER study: a multicenter, randomized, double-blind clinical trial of combination 
therapy with adalimumab plus methotrexate versus methotrexate alone or adalimumab alone in patients with early, aggressive rheumatoid arthritis who had not had previous methotrexate treatment. Arthritis Rheum 54:2637

Bruns A, Nicaise-Roland P, Hayem G, Palazzo E, Dieudé P, Grootenboer-Mignot S (2009) Prospective cohort study of effects of infliximab on rheumatoid factor, anti-cyclic citrullinated peptide antibodies and antinuclear antibodies in patients with long-standing rheumatoid arthritis. Joint Bone Spine 76:248-253

Burmester GR, Pratt AG, Scherer HU, Van-Laar JM (2012) Rheumatoid Arthritis: pathogenesis and clinical features. In: Bijlsma JWJ (ed) EULAR textbook on Rheumatic Diseases. BMJ group, London, pp 206-231

Canhao H, Rodrigues AM, Mourao AF, Martins F, Santos MJ, Canas Silva J, Polido Pereira J, Pereira Silva JA, Costa JA, Araújo D, Silva C, Santos H, Duarte C, da Silva JAP, Pimentel Santos FM, Branco JC, Karlson EW, Fonseca JE, Solomon DH (2012) Comparative effectiveness and predictors of response to tumour necrosis factor inhibitor therapies in rheumatoid arthritis. Rheumatology 51:2020-2026

Gartlehner G, Hansen RA, Jonas BL, Thieda P, Lohr KN (2006) The comparative efficacy and safety of biologics for the treatment of rheumatoid arthritis: a systematic review and metaanalysis. J Rheumatol 33:2398-2408

Gaujoux-Viala C, Smolen JS, Landewé R, Dougados M, Kvien TK, Mola EM, Scholte-Voshaar M, van Riel P, Gossec L (2010) Current evidence for the management of rheumatoid arthritis with synthetic disease-modifying anti-rheumatic drugs: systematic literature review informing the EULAR recommendations for the management of rheumatoid arthritis. Ann Rheum Dis 69:1004-1009

Grewal IS (2009) Overview of TNF superfamily: a chest full of potential therapeutic targets. Adv Exp Med Biol 647:1-7

Hetland ML, Christensen IJ, Tarp U, Dreyer L, Hansen A, Hansen IT, Kollerup G, Linde L, Lindegaard HM, Poulsen UE, Schlemmer A, Jensen DV, Jensen S, Hostenkamp G, Østergaard M (2010) Direct comparison of treatment responses, remission rates, and drug adherence in patients with rheumatoid arthritis treated with adalimumab, etanercept, or infliximab: results from eight years of surveillance of clinical practice in the nationwide Danish DANBIO registry. Arthritis Rheum 62:22-32

Hyrich KL, Watson KD, Silman AJ, Symmons DPM (2006) Predictors of response to anti-TNF-therapy among patients with rheumatoid arthritis: results from the British Society for Rheumatology Biologics Register. Rheumatology 45:155865

Klaasen R, Thurlings RM, Wijbrandts CA, van Kuijk AW, Baeten D, Gerlag DM, Tak PP (2009) The relationship between synovial lymphocyte aggregates and the clinical response to infliximab in rheumatoid arthritis: a prospective study. Arthritis Rheum 60:3217-3224

Klaasen R, Cantaert T, Wijbrandts CA, Teitsma C, Gerlag DM, Out TA (2011) The value of rheumatoid factor and anti-citrullinated protein antibodies as predictors of response to infliximab in rheumatoid arthritis: an exploratory study. Rheumatology 50:1487-1493

Kleinert S, Tony HP, Krause A, Feuchtenberger M, Wassenberg S, Richter C, Röther E, Spieler W, Gnann H, Wittig BM (2012) Impact of patient and disease characteristics on therapeutic success during adalimumab treatment of patients with rheumatoid arthritis: data from a German non-interventional observational study. Rheumatol Int 32:2759-2767

Kristensen LE, Kapetanovic MC, Gulfe A, Geborek P (2008) Predictors of response to anti-TNF therapy according to ACR and EULAR criteria in patients with established RA: results from the South Swedish Arthritis Treatment Group Register. Rheumatology 47:4959

Maini R, St Clair EW, Breedveld F, Furst D, Kalden J, Weisman M, Smolen J, Emery P, Harriman G, Feldmann M, Lipsky P (1999) Infliximab (chimeric anti-tumour necrosis factor alpha monoclonal antibody) versus placebo in rheumatoid arthritis patients receiving concomitant methotrexate: a randomised phase III trial. ATTRACT Study Group. Lancet 354:19329

Mancarella L, Bobbio-Pallavicini F, Ceccarelli F, Falappone PC, Ferrante A, Malesc D, Massara A, Nacci F, Secchi ME, Manganelli S, Salaffi F, Bambara ML, Bombardieri S, Cutolo M, Ferri C, Galeazzi M, Gerli R, Giacomelli R, Grassi W, Lapadula G, Cerinic MM, Montecucco C, Trotta F, Triolo G, Valentini G, Valesini G, Ferraccioli GF, GISEA group (2007) Good clinical response, remission, and predictors of remission in rheumatoid arthritis patients treated with tumor necrosis factor-alpha blockers: the GISEA study. J Rheumatol 34:16703

Mohammed RHA, Kewan HH, Bukhari M (2014) Assessment of the treat-to-target strategy in patients with refractory rheumatoid arthritis. Z Rheumatol 73(8):746-753

Nam JL, Winthrop K, Van Vollenhoven R, Pavelka K, Valesini G, Hensor EMA, Worthy G, Landewé R, Smolen JS, Emery P, Buch MH (2010) Current evidence for the management of rheumatoid arthritis with biological diseasemodifying antirheumatic drugs: a systematic literature review informing the EULAR recommendations for the management of RA. Ann Rheum Dis 69:976-986

Nozaki Y, Nagare Y, Hino S, Yano T, Kishimoto K, Shimazu H (2010) Therapeutic strategy and significance of serum rheumatoid factor in patients with rheumatoid arthritis during infliximab therapy. Nihon Rinsho Meneki Gakkai Kaishi 33:135-141

Nozaki Y, Kinoshita K, Funauchi M, Matsumura I (2013) A response of TNFa inhibitor treatment outcome in patients with rheumatoid arthritis. OA Immunology 1(1):1

Potter C, Hyric KL, Tracey A, Lunt M, Plant D, Symmons DP (2009) Association of rheumatoid factor and anti-cyclic citrullinated peptide positivity but not carriage of shared epitope or PTPN22 susceptibility variants, with anti-tumour necrosis factor response in rheumatoid arthritis. Ann Rheum Dis 68:69-74

Salgado E, Maneiro JR, Carmona L, Gómez-Reino J (2014) Rheumatoid factor and response to TNF antagonists in rheumatoid arthritis: systematic review and meta-analysis of observational studies. Joint Bone Spine 81:41-50

Scott DL, Kingsley GH (2006) Tumor necrosis factor inhibitors for rheumatoid arthritis. N Engl J Med 355:704-771

Smeets TJ, Kraan MC, Van Loon ME, Tak PP (2003) Tumor necrosis factor alpha blockade reduces the synovial cell infiltrate early after initiation of treatment, but apparently not by induction of apoptosis in synovial tissue. Arthritis Rheum 48:2155-2162

St Clair EW, Van der Heijde DM, Smolen JS, Maini RN, Bathon JM, Emery P, Keystone E, Schiff M, Kalden JR, Wang B, DeWoody K, Weiss R, Baker D (2004) Combination of infliximab and methotrexate therapy for early rheumatoid arthritis: a randomized, controlled trial. Arthritis Rheum 50:3432-3443

Taylor PC, Feldmann M (2009) Anti-TNF biologic agents: still the therapy of choice for rheumatoid arthritis. Nat Rev Rheumatol 5:578-582

Van der Heijde D, Klareskog L, Landewé R, Bruyn GA, Cantagrel A, Durez P, Herrero-Beaumont G, Fatenejad S (2007) Disease remission and sustained halting of radiographic progression with combination etanercept and methotrexate in patients with rheumatoid arthritis. Arthritis Rheum 56:3928-3939

van Gestel AM, Prevoo ML, van't Hof MA, van Rijswijk MH, van de Putte LB, van Riel PL (1996) Development and validation of the European League Against Rheumatism response criteria for rheumatoid arthritis. Arthritis Rheum 39:34-40

Wolfe F, Michaud K (2010) The loss of health status in rheumatoid arthritis and the effect of biologic therapy: a longitudinal observational study. Arthritis Res Ther 12:35

Yazdani-Biuki B, Stadlmaier E, Mulabecirovic A, Brezinschek R, Tilz G, Demel U (2005) Blockade of tumour necrosis factor \{alpha\} significantly alters the serum level of IgG- and IgA-rheumatoid factor in patients with rheumatoid arthritis. Ann Rheum Dis 64:1224-1226

\section{Submit your manuscript to a SpringerOpen ${ }^{\circ}$ journal and benefit from:}

- Convenient online submission

- Rigorous peer review

- Immediate publication on acceptance

- Open access: articles freely available online

- High visibility within the field

- Retaining the copyright to your article

Submit your next manuscript at $>$ springeropen.com 